\title{
DEFEATING PHENOMENAL CONSERVATISM
}

According to the phenomenal conservatives, beliefs are justified by non-doxastic states we might speak of as 'appearances' or 'seemings'. Those who defend the view say that there is something self-defeating about believing that phenomenal conservatism is mistaken. They also claim that the view captures an important internalist insight about justification. I shall argue that phenomenal conservatism is indefensible. The considerations that seem to support the view commit the phenomenal conservatives to condoning morally abhorrent behavior. They can deny that their view forces them to condone morally abhorrent behavior, but then they undercut the defenses of their own view.

\section{Introduction}

Consider the principle of phenomenal conservatism:

(PC) If it seems to you that $p$, then, in the absence of defeaters, you thereby have at least some degree of justification for believing $p .{ }^{1}$

Phenomenal conservatism is similar to generation conservatism insofar as these views agree that non-factive mental states provide prima facie justification for belief. ${ }^{2}$ Rather than say that believing $p$ is a prima facie justification for believing $p$, the phenomenal conservative focuses on appearance states distinct from belief, states we might pick out by saying 'It seemed that p' or 'It appeared that p' having had a conscious experience, an apparent memory, or an intuition about the right or the good. Appearances and seemings are supposed to be distinct from dispositions or inclinations to believe and distinct from beliefs. It can appear to you that $p$ even if you are convinced that $p$ is false and convinced that it only seems to you that $p$ because you were slipped a drug. Let us say that

\footnotetext{
${ }^{1}$ Huemer (2007: 30).

${ }^{2}$ The phenomenal conservative could say that beliefs are among the states that contribute prima facie justification, but they need not say this. Vahid (2004: 102) usefully distinguishes conservative views about that which generates justification from conservative views about the conditions under which a belief might justifiably persist in believing something already believed. It is unclear whether Harman (1986) accepts both the idea that a belief can generate a prima facie reason or whether in the absence of a prima facie reason not to believe, one is justified in continuing once the belief is in place. McGrath (2007) argues for a kind of conservatism that treats apparent memories as a source of justification or reasons for believing that is similar to $\mathrm{PC}$ in some respects and thinks that $\mathrm{PC}$ is useful in thinking about the justification of memorial belief.
} 
appearances or seemings are introspectively available non-factive representational states that can explain belief formation when believers take these appearances at face value. ${ }^{3}$

Because phenomenal conservatism is not committed to the claim that believing is its own prima facie justification, it avoids some of the objections that have been leveled against other versions of epistemological conservatism. ${ }^{4}$ Of course, even if it is true that the view avoids the difficulties that arise for some conservatives, this does little to recommend the view. Here, I want to look at the two defenses of PC that have surfaced in the literature. One argument purports to show that you cannot justifiably believe that $\mathrm{PC}$ is false on the grounds that it is self-defeating to deny PC. A second argument is supposed to show that PC captures an important internalist insight about justification other views do not. ${ }^{5}$ I shall argue that neither defense is successful.

It is easiest to see why these defenses of PC fail if we think about what a defender of PC would have to say in order to deal with an argument against their view. In $\S 3$, I present an argument that purports to show that PC would force us to condone all manner of morally abhorrent behavior because it denies there is any constitutive connection between the justification of normative belief and that belief's relation to objective principles and the normative status of the actions such beliefs rationalize. If this argument succeeds, it is a bit of a black eye for the view's chief defender. He is a critic of relativist or subjectivist views that deny that there are objective

\footnotetext{
${ }^{3}$ See Cullison (2010) and Huemer (2007: 31) for discussion. To simplify discussion, assume that if it looks to you as if $p$, the psychological states and events by virtue of which this is so do not depend upon whether you perceive $p$ or are undergoing a hallucination you cannot discriminate from a veridical perceptual experience. To simplify discussion, I do not discuss possible disjunctivist responses to Huemer's arguments for phenomenal conservatism. There are two features of PC worth noting. First, it only specifies conditions under which some degree of justification is had for believing. Huemer's remarks suggest that it might seem to you that $p$ and yet you might lack adequate justification for believing $p$ if the appearances are weak and wavering or if you have some sort of defeater. To keep things simple, let us assume that the seemings discussed in this paper are neither weak nor wavering. They are robust. I will mention when defeaters are present. Second, the view places no restrictions on the kinds of seemings or appearances and no restrictions on the beliefs. If it can seem to you that something is morally untoward or good, this can provide a prima facie justification for beliefs about the wrong or the good. The focus will be on beliefs about moral matters because these beliefs cause significant trouble for PC.

${ }^{4}$ Foley (1983) objects to the suggestion that believing $p$ is a prima facie reason to believe $p$ and one might think that what is attractive about PC is that it avoids his objection but captures some important insight conservative views are supposed to capture.

${ }^{5}$ For a discussion of the self-defeat argument, see Huemer (2007). Essentially the same argument was defended first in Huemer (2001). In Huemer (2006), he argues that PC captures an important internalist insight into the nature of justification and duty.
} 
moral standards by which we could condemn things like cannibalism and terrorism. ${ }^{6}$ Admittedly, the argument against PC rests on controversial assumptions, but if the argument against PC fails, it fails for reasons that undercut the defenses offered in support of PC. So, either there is overriding reason for rejecting PC because PC really does have abhorrent implications we know we should reject or the justification for PC has been undermined. Either way, the justification offered for PC has been defeated. And, since it is self-defeating to believe what you know you have no (undefeated) reason to believe, the phenomenal conservatives who read this should not be phenomenal conservatives until they come up with new reasons to believe their view.

\section{The Self-Defeat Argument}

The Self-Defeat Argument (SDA) is supposed to show that you cannot justifiably believe PC is mistaken. The believing of it, as it were, undermines the justification for thinking PC is false. Huemer remarks:

[T]he rejection of Phenomenal Conservatism is self-defeating, roughly, because one who rejected Phenomenal Conservatism would inevitably do so on the basis of how things seemed to himself; he would do so because Phenomenal Conservatism did not seem to him to be correct, or because it seemed to him to be incompatible with other things that seemed correct. Therefore, if this opponent of Phenomenal Conservatism were right, his belief in the negation of Phenomenal Conservatism would itself be unjustified (2007: 39).

We can reconstruct his reasoning as follows:

(1) Your beliefs are based on the way things seem to you.

(2) If your belief in $p$ is based on $\mathrm{X}$ and you believe that $\mathrm{X}$ is not a source of justification, your belief in $p$ is not justified for reasons of self-defeat.

(3) If you believe PC is mistaken, you believe that the way things seem to you is not a source of justification and believe this on the basis of the way things seem to you intuitively.

\footnotetext{
${ }^{6}$ Huemer (2005: 48-60).
} 
It is supposed to follow that:

(C) If you believe that PC is mistaken, your belief is not justified for reasons of self-defeat.

Does the SDA succeed? I think not. As stated, it has two significant defects. The first is that (2) is either false or it does not support the SDA's conclusion. The second is that (3) is false. Let's focus on (2) first. Audrey thinks that the word of a gambler is worthless. Coop is a gambler. He tells Audrey that $p$ is true. Audrey believes $p$ on the basis of Coop's testimony and believes she believes $p$ on the basis of his testimony. Is the justification for her belief in $p$ defeated for reasons of self-defeat? No, not if she does not believe that Coop is a gambler.

To se why this matters, let us suppose (1) is true. Suppose you believe PC is false on the basis of how things seem to you. If you believe you believe PC is false in part because it is false or in part because of some facts beyond facts about how things seem to you (e.g., facts that disconfirm PC, facts about the reliability of forming beliefs in response to appearances or seemings), you do not lack justification for reasons of self-defeat. You might harbor mistaken views about what justifies your beliefs, but it is not self-defeating to have false views about what justifies your beliefs.

To fix this problem, Huemer has to convince those who believe that PC is mistaken to believe that they believe PC is false on the basis of how things seem and not on the basis of any further facts:

(BS) If your beliefs are based on anything, they are based on appearances or seemings and nothing further. ${ }^{7}$

\footnotetext{
${ }^{7}$ I find talk about the basis of belief rather confusing. I tend to think that beliefs can be based on evidence and that evidence is propositional. Appearances or seemings are not propositions, but they might have propositional contents. If those who defend BS intend to deny that there is any sense in which beliefs are based on propositional evidence, I think BS is rather implausible. If we can say that there is a sense in which beliefs are based on other psychological states and another sense in which beliefs are based on the contents of those states, I think BS might be far less problematic. A further question is whether appearances or seemings have contents that are not themselves about appearances or seemings. If it seems to me that the cat is in the corner, can my reason for believing that my mouse is in danger be that there is a cat in the corner or that I can see that there is a cat in that corner? Or, is my reason that it appears there is a cat in the corner? It seems strange to think that all my evidence and reasons for belief are about appearances or seemings. Given Williamson's (2000) arguments for $E=K$, such a view would seem to amount to a form of skepticism. It also seems to sit quite badly with the phenomenology of ordinary reasoning. These are messes best bracketed for the time being. I defend aspects of Williamson's view while arguing that it is a mistake to take your evidence to include all of the propositions you know to be true in my (forthcoming).
} 
Unless you are convinced that BS is true, the SDA cannot get its hooks in you.

To be fair, Huemer does argue for BS. Even if his arguments for BS are successful, there is a second problem with the SDA. (3) is not true. Phenomenal conservatism is supposed to be an internalist view of justification. Huemer denies that the justification of our beliefs could depend upon factors beyond those that determine how things seem or appear. Externalists do not have to deny BS. Indeed, they do not have to deny PC. To see this, consider a fairly radical externalist view:

(KJ) You justifiably believe $p$ iff you know $p .^{8}$

$\mathrm{KJ}$ is an externalist view insofar as it says that the conditions that distinguish knowledge from ignorance are necessary for justified belief. So, KJ denies that there can be false, justified beliefs. On this view, you can justifiably believe $p$ on the basis of its seeming or appearing that $p$ if the appearance is veridical, but not if it is not veridical. Someone who accepts KJ could say that you believe on different bases when you veridically perceive that $p$ is true than you do when you mistakenly believe $p$ on the basis of hallucination, but they do not have to say this. Instead, they can say that your reasons for believing are the same in both case and the reason for believing is an appearance, a seeming, or a look. The justificatory difference between the case of knowledge and ignorance has to do with a difference in the defeaters that threaten justification. Those who defend KJ say that knowledge is the norm of belief and says that there is a reason not to believe $p$ if you are not in a position to know that $p$ is true. Reasons-for might be constituted by seemings or appearances and it might be that there is nothing more to reasons-for than apperances or seemings, but justification depends upon reasons-for and reasons-against. Reasons-against, KJ says, can be constituted by appearances or seemings, but they can also be constituted by worldly facts.

If the SDA is supposed to cause trouble for epistemic externalists, in addition to the argument for BS, we need an argument for the further thesis that the justification of belief depends entirely upon that belief's basis, how things seem, and nothing further:

(JB) The justification of your beliefs depends entirely upon the bases for your beliefs and your non-factive mental states. ${ }^{9}$

\footnotetext{
${ }^{8}$ See Sutton (2007) for a defense. For reasons discussed in my (2010), I do not find the arguments for $(\mathrm{KJ})$ or the knowledge account of assertion that Sutton takes to support (KJ) all that persuasive. I think it is possible to justifiably believe $p$ even if you do not know $p$ if the reason you do not believe $p$ is that your belief is not unGettiered.
} 
Now we can see why the SDA fails. The argument only applies to those who deny PC but accept JB and BS. Externalists do not accept JB and BS. Until Huemer can convince the externalists that they should accept both claims, the self-defeat charge does not stick. We shall see that his second defense of PC might offer support for JB and so might shore up the SDA. The important point is that everything hangs on whether that second argument succeeds. Before we get to this argument, I shall present an argument that seems to show that PC cannot give us a plausible epistemology of moral judgment.

\section{Must Phenomenal Conservatives Condone Cannibalism and Terrorism?}

According to PC, if it seems to you that $p$, you thereby have some degree of justification for believing $p$. There might be defeating conditions that prevent you from being fully justified in believing $p$, but if the view is an internalist view of justification, the defeating conditions ought to be characterized accordingly. The fact that a belief is mistaken, for example, cannot defeat the justification of a belief on an internalist view. Similarly, facts about the unreliability of a kind of appearance or appearance-producing process cannot defeat justification unless there is also evidence of unreliability.

Let me introduce our baddies, the cannibals and the terrorists. One reason terrorists engage in acts of terrorism is that they feel obliged to engage in acts of terrorism. One reason cannibals engage in acts of cannibalism is that they are hungry and they cannot think of any moral reason not to do so. Is it possible that the moral views of cannibals and terrorists are in line with the appearances and seemings PC has to say are sufficient to justify the beliefs of cannibals and terrorists? Can PC say that it is impossible for cannibals and terrorists to justifiably believe that they act rightly?

Our terrorists believe on the basis of a stock of seemings and appearances that there is a God and that we are God's property. This belief is not unique to religious fundamentalists that

\footnotetext{
${ }^{9}$ We should distinguish between the conditions that bear on the justification of your beliefs and the conditions that determine what justification (if any) you have for your beliefs. We can think of the latter in terms of reasons for believing and those might consist entirely of appearances or seemings even if the conditions that bear on the justification of your beliefs does not just consist of appearances or seemings. The conditions that determine whether there are defeaters, whether your evidence is strong enough, whether your beliefs are held for good reasons, etc..., might be conditions that bear on the justification of your beliefs even if they are not justifications for believing what you do.
} 
commit acts of terrorism. They believe that God demands that they target innocents for religious and political causes. This is an empirical belief. I cannot see how an internalist can deny that it is possible for someone to justifiably believe this given the 'right' appearances and seemings. Since they think we are all God's property, they think we cannot have the kinds of rights that make it wrong to use us as means to divinely commanded ends. Can the phenomenal conservative say that it is impossible to have a configuration of non-factive mental states that would make it reasonable to believe all these things? That would be ad hoc. It would also be ad hoc to say that anyone in such states would have defeaters for his beliefs. Our terrorists are culturally isolated. I think PC has to concede that it is possible for someone to rationally believe they are obliged to engage in acts of terrorism given what they say makes beliefs reasonable. To deny this would be to deny on apriori grounds that subjects could have the kinds of psychological profiles I have described here.

As for our cannibal, our cannibal might be aware of those states of affairs we think provide agent neutral reasons to take strangers to have the kind of moral status that makes it wrong to eat them without having any intuition, appearance, or seeming that would let us say of her that it seems to her that she has a reason to care about a stranger or suspect that she should care about a stranger. We can throw in the further beliefs that finding an alternative source of food would be a bother and the belief that people are tasty. We can isolate our cannibal to remove defeaters. Her victims struggle, of course, but as they do not speak our cannibal's language, she cannot consider their carefully worked out arguments about the dignity of persons or the moral significance of sentience as she tries to kill them. If it seems to the cannibal there is no reason not to do what cannibals do and some relatively strong reason to do what the cannibal does, it seems there is nothing that a phenomenal conservatives can say to show that it is impossible for someone to be justified in believing that she acts rightly in engaging in acts of terrorism.

With this in mind, consider the following argument against PC:

(1) If the agent justifiably judges she should $\mathrm{V}$, the agent is justified in $\mathrm{V}$-ing (JJ).

(2) PC implies that an agent can (if she has the right combination of appearances and seemings) justifiably judge that she ought to engage in acts of cannibalism or terrorism.

(C) PC implies that any agent who justifiably judges that he ought to engage in acts of terrorism or are right to engage in acts of 
cannibalism acts permissibly in acting in accordance with these judgments.

Huemer rejects the sort of crude relativist view of moral obligation that condones cannibalism and terrorism, as he should. ${ }^{10}$ The question is whether he has the right to do so given his commitment to PC. It seems that to deny (2), he would have to deny that certain combinations of mental states described above are possible. So, it looks like he would have to deny JJ to block the objection.

$\mathrm{JJ}$ is controversial, so maybe he should deny it. An initial worry about JJ is that while there might be some sense in which it is intuitively right to say that, rationally speaking, if you justifiably believe you ought to $\mathrm{V}$, this is what you ought to do. ${ }^{11}$ But, you cannot define the most fundamental sense of "ought" in terms of justified belief about what you ought to do. It would be pathetically circular to say that what you ought to do, fundamentally, is what you justifiably believe you ought to do. For what does the belief that you ought to do something come to on such a view? Justifiably believing you ought to $\mathrm{V}$ is just justifiably believing that you justifiably believe you ought to $\mathrm{V}$.

I agree that we cannot define "ought" in terms of justified beliefs about what you ought to do and if defending JJ required defending that hopeless view, defending JJ would be a hopeless enterprise. Instead, this is the thought behind JJ. Suppose that whether 'You ought/oughtn't to V' depends upon the reasons that count in favor of V-ing and count against V-ing. This is true, let's say, whether ' $V$ ' is a verb that the epistemologists care about (e.g., 'believe', 'infer', 'judge') or a verb the ethicists care about (e.g., 'kiss', 'kick', 'kill'). Do the reasons that bear on whether to V have to pass through an epistemic filter? ${ }^{12}$ Do they have to be accessible? JJ does not tell us, really. JJ comes out as true if we accept:

(RA) If $\mathrm{R}$ is a reason that bears on whether $\mathrm{S}$ is to $\mathrm{V}, \mathrm{R}$ must be accessible to $\mathrm{S}$.

If some fact is inaccessible to you or justifiably believed not to be a fact, RA says that such a fact cannot constitute a reason that bears on whether to act or to believe. Inaccessible facts might make an act or a belief unfortunate, but RA says that such facts have no deontic significance. Ignorance obviates the need to justify acts and beliefs that are unfortunate in light of facts unavailable to the agent.

\footnotetext{
${ }^{10}$ Huemer (2005).

${ }^{11}$ Thanks to an anonymous referee for raising this worry.

${ }^{12}$ Dancy (2000) defends the view that reasons are facts about the situation and argues that only the facts that pass through an epistemic filter bear upon the rightness of an action.
} 
If RA is false because neither epistemic nor practical reasons need to be accessible to you to bear on whether to act or believe, JJ might turn out to be true if, say, $\mathrm{KJ}$ is true. When there is a decisive case against V-ing grounded in facts inaccessible to you, you oughtn't V and by virtue of the factivity of 'knowledge', there is a decisive case against believing you ought to V. I haven't defined 'ought' in terms of justified beliefs about what ought to be done; rather, JJ is a consequence of thinking that epistemic and practical reasons are similar in certain respects.

The most obvious way to attack JJ is to attack RA and to argue that, say, epistemic reasons have to be accessible to bear on whether to believe but practical reasons can bear on whether to act whether they are accessible or not. So, consider two views:

(RAE) If $\mathrm{R}$ is an epistemic reason that bears on whether $\mathrm{S}$ is to $\mathrm{V}$, $\mathrm{R}$ must be accessible to $\mathrm{S}$.

(RAP) If $\mathrm{R}$ is a practical reason that bears on whether $\mathrm{S}$ is to $\mathrm{V}, \mathrm{R}$ must be accessible to $\mathrm{S}$.

Someone who denies RA to deny JJ asserts that RAE is true (or true enough) and that RAP is false. I shall mention two problems with this view.

With apologies to Judith Thomson, consider this dialogue:

Tom: I've been given orders to drop bombs over Bad. I think our cause is just, but if I drop the bombs over Bad, these bombs will destroy the munitions factory and a hospital. I just don't know what to think about this.

Dick: You should think of this as a necessary evil.

Tom: I'm back from the strike on Bad. We destroyed the munitions factory, but we did destroy the hospital.

Harry: What a horrible thing to do! You should never drop bombs near a hospital.

Tom: A little help, Dick.

Dick: Oh, I agree with Harry. He’s the ethicist.

Tom: But you told me I should drop the bombs, that it was a necessary evil. 
Dick: No, no, no. I told you that you should think of dropping the bombs as a necessary evil. Harry and I agree on that, right Harry?

Harry: Yes, absolutely. I don't do much epistemology, but given how things seemed to you at the time, that is precisely what you should have believed. But, as Dick would agree, I'm better at ethics. We agree that you shouldn't have dropped the bombs. Isn't that right, Dick?

Dick: Precisely. We ethicists and epistemologists agree not to disagree on such matters. Epistemically, everything was in order. You believed just what you should have. Practically, everything went horribly wrong. You should have resisted, Tom, you should have kept yourself from flying that plane.

Tom: You mean, I should have kept myself from flying the plane while believing I should fly the plane? And I should have believed that I should fly the plane.

Dick: Yes, exactly.

Harry: Exactly.

My sympathies are with Tom. ${ }^{13}$ I do not approve of bombing hospitals, but I also think it is strange to think that reason can be divided against itself in the way it would have to be for Dick and Harry to be right to agree not to disagree. If the weightier reasons made it wrong to drop the bombs even if Tom was non-culpably ignorant of the fact that the reasons-against bombing were the weightier reasons, the weightier reasons made it wrong to judge that he should drop the bombs. If, however, by virtue of the inaccessibility of the comparative weight of these reasons we think his judgment is

${ }^{13}$ An anonymous referee noted that while there is something strange to the suggestion that Tom can both justifiably believe his beliefs are justified while believing that his actions are not when those beliefs rationalize the actions, this might not be due to the fact that the fact that the Tom ought not V commits us to saying that Tom ought not judge that he ought to V. It was suggested that the oddity might be related to something like Moorean absurdity. The trouble with this suggestion is that Tom is retrospectively evaluating his attitudes and actions. Just as there is nothing absurd in saying I used to believe $p$ but was mistaken in so believing, it is hard to see what would account for the absurdity in the judgment that I should not have V'd but should have thought that I should have. 
justified, why should we then say that the comparative weight of these reasons determine whether his actions were justified? This fact about the weight of reasons was not just something he did not know about, it was something he justifiably took to be a certain in way in deliberating about what to do. If beliefs do not call for justification in light of inaccessible facts, why do actions call for justification in light of these inaccessible facts?

The problem is not just that this seems intuitively strange. Theoretically it is hard to see how to defend the view that accepts RAE but rejects RAP. ${ }^{14}$ It seems that it cannot just be a brute fact that practical reasons need not be accessible in the way that epistemic reasons have to be. Why do inaccessible facts make beliefs regrettable without threatening their justificatory status when these facts threaten the justificatory status of actions by making them regrettable? If you want to explain something about practical and epistemic reasons, you can either ground that explanation in general features of reasons of all kinds or focus on the epistemicness/practicalness of the reasons. We cannot explain the differences by focusing on general features of reasons of all kinds. After all, we are trying to explain a difference, not a similarity. I do not think the epistemicness of the epistemic reasons can shoulder the explanatory burden because the difference between epistemic reasons and practical reasons seems to be that the former have to do with the pursuit of truth and the latter have to do with the pursuit of the good. There is nothing in this difference that explains why one kind of reason needs to be accessible while the other need not be because the good and the true are both external to us.

One potential difference between RAE and RAP is that, arguably, the relation between beliefs and the reasons that justify them are relations between mental states. Assuming BS, our beliefs are based on seemings or appearances. Reasons for action, however, have to justify changing the world, not just changing our own minds. This makes it more plausible to think that the relations that have to be in place to act justifiably include more than just relations amongst mental states. $^{15}$

One worry I have about this line of response is that it might make us say something strange about the reasons that motivate intention and bear on whether to intend. Remember the toxin

\footnotetext{
${ }^{14}$ I agree with Gibbons (2010) who thinks that we should expect that at some abstract level, we should expect there to be similarities between reasons for belief and action because in both cases we are dealing with reasons. Here, I want to say something stronger. If there is nothing that could explain the (alleged) difference between reasons for belief and action, since it could not be a brute fact, there is not a difference with respect to accessibility.

${ }^{15}$ Thanks to an anonymous referee for raising this worry.
} 
puzzle. ${ }^{16}$ An eccentric billionaire offers you a large sum of money to form the intention to drink a mildly toxic poison. If you form this intention by midnight tonight, you do not need to drink the toxin when it is presented to you tomorrow at noon. At that point, you can pitch the toxin and take the check. The deal is off if you forget the conditions of the deal or if you add extra incentives to give you reason to carry out your intention. A standard position on the toxin puzzle is that you cannot form the prize-winning intention because you know now that when the time comes, there is not only no reason not to act, there is compelling reason not to act. This explanation as to why you cannot form the intention to perform the action and win the prize assumes that the reasons that bear on whether to $\mathrm{V}$ bear on whether to intend to $\mathrm{V} .{ }^{17}$

If the reasons that bear on whether to $\mathrm{V}$ thereby bear on whether to intend to $\mathrm{V}$, but we reject JJ, we have to say that the reasons that bear on whether to believe you should $\mathrm{V}$ do not bear on whether to intend to V. There will be overlap, but only partial overlap, and sufficient reason to judge that you should $\mathrm{V}$ will not provide sufficient reason to intend to $\mathrm{V}$. Intuitively, it seems that if you shouldn't intend to V, you shouldn't believe you should V.

I cannot say that these considerations constitute a compelling case for JJ, but hopefully I have offered some motivation for thinking that the deontic standings of beliefs and the actions they rationalize are linked in the way JJ suggests. PC is a theory of epistemic justification, not a theory of the relation between the justificatory statuses of beliefs and the actions they rationalize. So, PC does not entail JJ and you might think phenomenal conservatives are free to deny JJ. They are, but we shall see that if they deny JJ, they undercut the argument for JB. Both defenses of PC depend on JB, so this would undercut both defenses of PC.

\section{The Internalist Intuition}

Huemer thinks that externalist accounts of justification are deeply counterintuitive. In this section, we shall look at the intuition that he thinks motivates internalist theories of justification. Remember that one view his SDA does not touch grants that seemings or appearances are what our beliefs are always based on and grants that they are what provide us with reasons to believe. The externalist denies that JB is true and either argues that there are external conditions that enable

\footnotetext{
${ }^{16}$ Kavka (1983).

${ }^{17}$ See Shah (2008). An anonymous referee suggested that we might approach this puzzle by saying that you cannot form the intention to $\mathrm{V}$ if you know you will not later $\mathrm{V}$. Even if this is so, we might want to explain why this is so and Shah's explanation strikes me as being rather plausible.
} 
internal conditions to confer justification or external conditions that can defeat the justification appearances provide.

The internalist intuition he thinks rules out all versions of externalism is this one:

[T]here cannot be a pair of cases in which everything seems to a subject to be the same in all epistemically relevant respects, and yet the subject ought, rationally, to take different doxastic attitudes in the two cases - for instance, in one case to affirm a proposition and in the other to withhold. ${ }^{18}$

The crucial internalist intuition is that there can only be a difference in the deontic status of two of your beliefs (e.g., one is permissible to hold, but one is not permissible to hold) if there is something available to you that would indicate to you that there is this difference in deontic status. Why should we believe this? Huemer thinks that the absurdity of the externalist view that denies this is evidenced by the absurdity of the following speech:

I seem to be aware that $p$ just as I seem to be aware that $q$. These seemings both seem equally reliable to me, and in general, seem the same in all epistemically relevant respects. However, I believe $p$ but do not and will not believe $q$. I don't seem to have any reason to think that the appearance of $p$ is more reliable or more trustworthy than the appearance of $q$. I just accept the one content but not the other, and for no apparent reason. ${ }^{19}$

He seems to think that the externalist agrees that these claims are all true and so should think this is perfectly coherent. As it seems positively incoherent, this is supposed to count against the epistemic externalist view.

I fear that this argument might prove too much. Some externalists about the justification of action deny JJ. ${ }^{20}$ They might say that the conditions that determine whether your normative judgments are justified do not determine whether your actions are justified. The conditions that determine whether your normative judgments are justified supervene upon your evidence but facts about the consequences of your actions determine whether your actions are justified. Or, perhaps your normative judgments are justified when formed by reliable processes of belief formation. It

\footnotetext{
${ }^{18}$ Huemer (2006: 152).

${ }^{19}$ Paraphrased from Huemer (2006: 151).

${ }^{20}$ One of the leading epistemic internalists denies JJ. See Feldman (1988) for a discussion.
} 
surely does not follow from the fact that you justifiably judge that you should V that you are justified in V-ing just as it does not follow from the fact that you justifiably judge that it is raining that it rains. It doesn't matter which of these views is correct. The point is that JJ implies implausibly that there cannot be false, justified beliefs about what it would take to act with justification.

Consider the following argument against the externalist view that rejects $\mathrm{JJ}$ : I seem to be aware that V-ing is obligatory just as I seem to be aware that Y-ing is obligatory. These seemings both seem equally reliable to me, and in general, seem the same in all epistemically relevant respects. However, I shall V but shall not Y. I don't see any reason, moral or otherwise, to V but not $\mathrm{Y}$. Indeed, so far as I'm concerned, there is equally good reason to do both, no reason not to do either, and it would be just as easy to do both as it would be to do just one. And, there is nothing epistemically amiss with my beliefs about which acts to perform: I do believe that I am obliged to do both. I just will $\mathrm{V}$ but will not $\mathrm{Y}$, and for no apparent reason.

This speech is just as absurd as the first. Does the first absurd speech establish JB? It might, but only if the second establishes JJ. From my point of view, I see no difference between the speeches and the support they provide to JJ and JB respectively. Anyone who takes the internalist intuition seriously and is like me in these respects ought to either accept JJ and JB or suspend judgment on both until they can find some difference between the two cases for JJ and JB. If proponents of $\mathrm{PC}$ accept both $\mathrm{JJ}$ and JB, then they can run the internalist argument for PC while opponents of PC can run the objection that PC condones cannibalism and terrorism. What do you do when appearances, seemings, and intuitions conflict? If you go with the strongest, PC loses. If proponents of $\mathrm{PC}$ concede that they do not have a case for JB, neither of the defenses offered for PC succeeds. The justification for PC is defeated either way. 
In response, Huemer could say that there is a difference in the two absurd speeches. I do not know what that difference would be, but I also think it does not matter if there is a difference. The absurdity of these speeches is not evidence for JB or JJ. ${ }^{21}$ Consider:

(1) There is a deontic difference between V-ing and Y-ing, but I have no reason to believe there is.

(2) There is a biological difference between this critter and that critter, but I have no reason to believe there is.

Both utterances would be absurd, but the absurdity of (2) lends no support to the view that biological differences between critters must be accessible or available to us. These are both Moorean absurdities. The absurdity tells us nothing about the way that the truth-conditions of the conjuncts are related. If the absurdity of (1) really had to do with some important fact about obligations, restating (1) in the third-person should also seem absurd:

(3) There is a deontic difference between his eating a person and his eating a papaya, but he isn't aware of any of the reasons as to why this is that would make it reasonable for him to think this.

Isn't that precisely what we should say about the cannibal? We can try the same thing with beliefs rather than actions. This seems absurd.

(4) There's an epistemic difference between my believing that the next marble will be black and my believing that the next hand I'm dealt will be a winner, but I'm not aware of any reason to believe there is such a difference.

This seems perfectly fine:

(5) There's an epistemic difference between his believing that the next marble will be black and his believing that the next hand he's dealt will be a winner. But, he's not aware of any reason these beliefs differ and it's not for a lack of trying on his part. He simply doesn't know that the there's a difference between good inductive inference and inferences that commit the gambler's fallacy.

\footnotetext{
${ }^{21}$ An anonymous referee suggested that there might be something pragmatically defective with these speeches. I agree.
} 
Not only does (5) seem fine, if the absurdity of (4) was sufficient evidence for (5), you would have to say that beliefs arrived at by means of inductive inference are only justified if the subject is aware of reasons to think such beliefs differ epistemically from those arrived at by means of inference that commit the gambler's fallacy. That seems overly demanding.

\section{Conclusion}

If the internalist intuition supports JB and JJ, there is a perfectly straightforward reductio argument against PC. PC condones cannibalism and terrorism. Is it better to be a phenomenal conservative and condone cannibalism than to commit to neither? If the internalist intuition supports neither JJ nor JB, then none of the arguments offered in support of Huemer's internalist account of justification succeed. The challenge is to find some rationale for denying JJ that does not threaten to undermine the case for JB. The persistent worry is that defenses of JB will do too much and support JJ while criticisms of JJ will do too much and threaten JB. My own view is that the case for $\mathrm{JJ}$ is pretty strong and similar problems arise for views that deny that the justificatory status of a normative judgment depends upon whether the agent's judgments conform to objectively correct normative principles. ${ }^{22}$ A full defense of $\mathrm{JJ}$ is beyond the scope of this paper. So, I offer JJ as a challenge to moral epistemologists who agree that the cannibals and terrorists behave horribly even if they deliberate carefully and it seems to them that they are within their rights in acting as they do. If ignorance of normative principle does not justify action or obviate the need to justify action, how does it undercut the need to justify normative judgments that express the subject's commitment to the wrong values? ? $^{23}$

\section{References}

Audi, R. 2004. The Good in the Right. Princeton, NJ: Princeton University Press.

\footnotetext{
${ }^{22}$ Bedke (2008) attacks Audi's (2004) epistemology of moral judgment on the grounds that Audi's view gives us an account of how we can justifiably accept true normative principles but not how we can justifiably believe normative propositions that conflict with these objectively true principles. I don't know if this was intended as a feature of Audi's view, but I think it's far from obvious that it's a bug.

${ }^{23}$ I would like to thank Andrew Cullison, Nathan Hanna, Michael Huemer, and Mark van Roojen for discussing these issues with me. Also, I want to thank two anonymous referees for this journal for providing me with helpful written comments on earlier drafts, they were very much appreciated.
} 
Bedke, M. 2008. Ethical Intuitions: What They Are, What They Are Not, and How They Justify. American Philosophical Quarterly 45: 253: 70.

Cullison, A. 2010. What Are Seemings? Ratio 23: 260-74.

Feldman, R. 1988. Subjective and Objective in Ethics and Epistemology. The Monist 71: 405-19.

Foley, Richard 1983. Epistemic Conservatism. Philosophical Studies 43: 165-82.

Gibbons, J. 2010. Things That Make Things Reasonable. Philosophy and Phenomenological Research 81: 335-61.

Harman, G. 1986. Change in View. Cambridge, MA: MIT University Press.

Huemer, M. 2001. Skepticism and the Veil of Perception. Lanham, MD: Rowman \& Littlefield. . 2005. Ethical Intuitionism. New York: Palgrave MacMillan. . 2006. Phenomenal Conservatism and the Internalist Intuition. American Philosophical Quarterly 43: 147-58.

. 2007. Compassionate Phenomenal Conservatism. Philosophy and Phenomenological Research 74: $30-55$.

Kavka, G. 1983. The Toxin Puzzle. Analysis 43: 33-6.

Littlejohn, C. 2010. Moore's Paradox and Epistemic Norms. Australasian Journal of Philosophy 88: 79-100. . Forthcoming. Evidence and Knowledge. Erkenntnis.

McGrath, M. 2007. Memory and Epistemic Conservatism. Synthese 157: 1-24.

Shah, N. 2008. How Action Governs Intention. Philosopher's Imprint 8: 1-19.

Sutton, J. 2007. Without Justification. Cambridge, MA: MIT University Press.

Vahid, H. 2004. Varieties of Epistemic Conservatism. Synthese 141: 97-122.

Williamson, T. 2000. Knowledge and its Limits. New York: Oxford University Press. 